\title{
The Association between Relative Age Effect, Goals Scored, Shooting Effectiveness and the Player's Position, and her Team's Final Classification in International Level Women's Youth Handball
}

\author{
Yzan Saavedra ${ }^{1}$, Jose M. Saavedra ${ }^{2}$ \\ Affiliations: 'Rosalía de Castro Multilingual Institute, Santiago de Compostela, Spain. ${ }^{2}$ Reykjavik University, School of \\ Social Sciences, Sports Science Department, Physical Activity, Physical Education, Health and Sport Research Centre \\ (PAPESH), Reykjavik, Iceland
}

Correspondence: J.M. Saavedra, Reykjavik University, School of Social Sciences, Sports Science Department, Physical Activity, Physical Education, Health and Sport Research Centre (PAPESH), Menntavegur 1, Nauthólsvík, 101 Reykjavík, Iceland. Email: saavedra@ru.is

ABSTRACT The objectives of this study were (i) to determine whether there is a relationship between the relative age effect (RAE) and the final classification of the teams, player's positions, number of goals scored, and shooting effectiveness, and (ii) to determine whether there are differences in the number of goals scored and shooting effectiveness depending on the final classification and player's positions. The study subjects were 380 players who took part in the 2018 Women's Youth World Handball Championship. The independent variables were the relative age effect and the number of goals and shooting effectiveness of each type of shot. The dependent variables were the player's position and the team's final classification. To investigate the relationship between the RAE and the team's final classification, player's position, goals scored, and shooting effectiveness, contingency tables were drawn up and subjected to a chi-squared test. The dependence of the differences in goals and shooting effectiveness on the team's final classification and the player's position was studied by means of an ANOVA with a Tukey post hoc test. For the sample overall, there was no RAE, only an association between the classification and the year of birth, with more players born in the senior year in the teams ranked from 1st to 8th place than in those classified from 9th to 24th place. The teams classified from 1 st to 4 th had more significant numbers of several variables. There were differences in goals and shooting effectiveness, depending on the player's position.

KEY WORDS performance, game-related statistics, throwing, back, wing, pivot

@MJSSMontenegro

RELATIVE AGE EFFECT IN WOMEN HANDBALL PLAYERS

http://mjssm.me/?sekcija=article\&artid=188

\section{Introduction}

Team-handball (handball) emerged in the early 19th century in Scandinavia. It became an Olympic sport for men in 1972 and for women in 1976. A handball game lasts for two periods of 30 minutes. It is played on an indoor court of $40 \times 20 \mathrm{~m}$. Each team plays with seven players (six in the field plus the goalkeeper), the objective being to score more goals than the opponent to win the match. Players are organized defensively around the D-zone, which is marked six metres from the goalposts. Only the goalkeeper can be in contact with the ground within this zone during play. Handball, like other team sports, has well-defined field positions with differentiated roles: goalkeeper, back (centre, right, left), wing (right, left), and pivot.

Handball can be considered an intermittent contact sport that intercalates actions of high intensity (sprints, jumps, shots, and blocks) with those of medium/low intensity (walking or jogging movements, passes). Hand-

Received: August 092019 | Accepted after revision: September 28 2019 | First published online: March 012020

(c) 2020 by the author(s). License MSA, Podgorica, Montenegro. This article is an open access article distributed under the terms and conditions of the Creative Commons Attribution (CC BY).

Conflict of interest: None declared. 
ball performance is influenced by various factor: individual (coordination, strength, endurance, constitution-disposition, nutrition), collective (social, tactics, cognition), and environmental (ambient conditions, material) (Wagner, Finkenzeller, Wurth, \& von Duvillard, 2014). While players are in their developmental ages, individual factors, to a large extent, depend on maturation and growth, and these do not have any linear relationship with chronological age (Balyi \& Way, 2009). Since the rhythms of maturation and growth differ from individual to individual, young people with the same chronological age may have relevant differences. To avoid these differences, some federations organize their competitions according to the year of birth (in swimming, for example, the minimum mark required to take part in certain championships depends on the year of birth), while other federations organize their competitions by "pooling together" in the same age category players born in two different years. This is the case of the International Handball Federation, which, in international competitions, groups together players born in two different years, with the even year always being the senior year. Thus the categories in men are Junior (Under-21) and Youth (Under-19), and in women are Junior (Under-20) and Youth (Under-18). This organization, therefore, has players competing together who are up to 24 months apart in their chronological age.

The age difference between subjects of a given group relative to a cut-off point is known as the Relative Age, and the potential advantage that this difference may produce is known as the Relative Age Effect (RAE) (Andronikos, Elumaro, Westbury, \& Martindale, 2016). The first studies on RAE were done in the field of education. They showed that schoolchildren who were older at the beginning of the school year had better academic performances (Davis, Trimble, \& Vincent, 1980). In the field of sports, there have been RAE studies in basketball (Delorme \& Raspaud, 2009), football (Yague, de la Rubia, Sánchez-Molina, Maroto-Izquierdo, \& Molinero, 2018), ice hockey (Weir, Smith, Paterson, \& Horton, 2010), volleyball (Campos, Stanganelli, Rabelo, Campos, \& Pellegrinotti, 2016), and swimming (Cobley et al., 2019). In most cases, the RAE was analysed according to the trimester of birth (Q1, January-March; Q2, April-June; Q3, July-September; Q4, October-December). It was found that sportspersons born in the first or second trimesters of the year have a more significant presence in teams than those born in the third or fourth trimesters (Schorer, Baker, Busch, Wilhelm, \& Pabst, 2009), with differences depending on the player's position (Yague et al., 2018) and even on their geographical location (Leite et al., 2018). The RAE decreases with increasing age of the sportsperson (Bjørndal, Luteberget, Till, \& Holm, 2018). There have been few studies of RAE in handball. One study of German players (men and women) found that, for both sexes, as the players became older, the percentage of players born in the first trimester decreased (Schorer et al., 2009). Similarly, a study of Spanish international (male) players found that, in the junior (under-20) and cadet (under-16) categories, the players were born mostly in the first trimesters of the year, although there were no such differences in the senior teams (Sánchez-Rodríguez, Grande, Sampedro, \& Rivilla, 2013). Similar results were found in a sample of Danish men at the international level (Wrang et al., 2018) and in Spanish players at the regional level (Gómez-López, Angosto, Granero-Gallegos, \& Chirosa, 2017).

The handball action par excellence is the shot since its ultimate objective is to score a goal. This action differs according to the player's position. Thus, $75 \%$ of the shots in a match are made after a jump, an action that usually corresponds to the back and wing players, while the slowest shots are those of the pivot (Wagner et al., 2014). In recent years, there have been studies of the RAE in handball and its relationship with other variables (not only with the selection of players for a national team or club). One (Fonseca, Figueiredo, Gantois, de Lima-Junior, \& Fortes, 2019) found that the RAE also influences the player's position (men) (U19), with more back and wing players having been born in the first and second trimesters, and similar data had been reported in a study of senior players (men) at international level (Karcher, Ahmaidi, \& Buchheit, 2014). Another study analysed the relationship between the number of games played and the trimester of birth in an international sample of Norwegian players, finding that players born in Q1 (January-March of the senior year) played more games than those born in Q8 (October-December of the junior year) in the women's youth category (Bjørndal et al., 2018). Likewise, a study of Brazilian U13 male players found that those born in Q1 (January-March) played longer than those born in Q4 (October-December) (Leonardo, Lizana, Krahenbuhl, \& Scaglia, 2018).

Although in recent years the number of studies being published has been increasing, we found none analysing the relationship between the RAE and the team's final classification, player's position, number of goals, or shooting effectiveness. Thus, the objectives of the present study were (i) to determine whether there is a relationship between the relative age effect and the team's final classification, player's position, number of goals scored, and shooting effectiveness, and (ii) to determine whether there are differences in the number of goals scored and shooting effectiveness depending on the final classification and player's position.

\section{Methods}

Participants

The sample comprised all the players $(n=380)$ of the 24 national teams that participated in the 7th Women's Youth World Handball The teams participating in this championship were Angola, Argentina, Austria, Chile, Croatia, Denmark, Egypt, France, Germany, Japan, Kazakhstan, Korea, Montenegro, Netherlands, Norway, People's Republic of China, Poland, Romania, Russia, Slovakia, Spain, Sweden, and Tunisia.

\section{Procedures}

The data were obtained from the official website of the International Handball Federation (IHF, 2018). They 
were entered into Excel by one of the authors (YS), then another of the authors (JMS) randomly reviewed them to detect potential errors. No informed consent or approval from the Ethics Committee was required as this was public domain data accessible on the Web. On this website, there is no prohibition, either explicit or implicit, to use these data for scientific purposes. In any case, the data were treated conjointly, without reference to each player's name. The analysis of public data taken from websites is habitual in the field of handball (Ferrari, Sarmento, \& Vaz, 2019; Fonseca et al., 2019; Gómez-López et al., 2017; Sánchez-Rodríguez et al., 2013).

The independent variables of this study were the players' year, semester, and trimester of birth (RAE), and the number of goals and shooting effectiveness of each type of shot (game-related statistics). The RAE was categorized into different groups depending on the year of birth (2000, 2001 or 2002), the semester of birth (S1, January-June; S2, July-December), and the trimester of birth (Q1, January-March; Q2, April-June; Q3, July-September; Q4, October-December). These game-related statistics (Table 1) were already of general use among women's handball coaches and technicians and had been used in earlier studies (Melekatos, Vagenas, \& Bayios, 2011). The dependent variables of the study were the team's final classification (1st to 4th place, 5th to 8 th place, 9th to 16th place, 17th to 24 th place) and the player's position (goalkeeper, centre back, left and right backs, left and right wings, pivot). The goalkeeper position was not taken into account for the analyses of goals and effectiveness.

\section{Statistical analysis}

Contingency tables were constructed, and the chi-squared $\left(\chi^{2}\right)$ values were calculated to determine the relationship between the RAE (players' birth year, semester, and trimester) and the team's final classification, the player's position, goals scored, and shooting effectiveness. The basic statistical descriptors (mean and standard deviation) were calculated for the goals and shooting effectiveness variables. Finally, to determine the differences in goals and shooting effectiveness based on the team's final classification and player's position, the data

\section{TABLE 1. Definitions of the shots' variables}

Variable Definition

Total goals

Total shots

6-m goals

6-m shots

7-m goals

7-m shots

9-m goal

9-m shots

Wing goals

Wing shots

Fast-break goals

Fast-break shots

Breakthrough goals

Breakthrough shots
Number of goals scored.

Percentage of converted shots relative to the number of shots made.

Number of goals scored at $6 \mathrm{~m}$. The shot was made at an angle greater than $45^{\circ}$ from the left or the right.

Percentage of converted shots at 6-m relative to the number of such shots made.

Number of goals scored from the penalty line $(7 \mathrm{~m})$.

Percentage of penalties converted relative to the number of penalties taken.

Number of goals scored at $9 \mathrm{~m}$. The shot was made by a backcourt player either (a) over or through the defence, or (b) after a breakthrough but with another defending player in front.

Number of goals scored at $9 \mathrm{~m}$. Percentage of converted shots at $9 \mathrm{~m}$ relative to the number of such shots made.

Number of goals scored from the wing area, the zones within an angle of $45^{\circ}$ from the left and right without a defending player in front.

Percentage of converted shots from the wing area relative to the number of such shots made.

Number of goals scored in a fast-break situation - rapid switch from defence to attack with the defence still disorganized.

Percentage of converted fast-break shots relative to the number of such shots made.

Number of goals scored in a breakthrough situation - (a) by the backcourt players after a breakthrough in the 9-m zone without a defending player in front, (b) by the pivot after a 1:1 situation, (c) by the left or right back after breaking through 1:1 situations.

Percentage of shots converted in a breakthrough situation relative to the number of such shots made.

were subjected to an ANOVA with a Tukey post hoc test. The eta-squared $\left(\eta^{2}\right)$ statistic, which describes the proportion of the variance attributable to a given factor, was also calculated. A p-value $<0.05$ was considered to be statistically significant. The statistical analysis was performed with the SPSS software package, version 15.0 (SPSS Inc., Chicago, IL, USA).

Results

Table 2 presents the distribution of the overall sample by year, semester, and trimester of birth. The greatest percentages of players correspond to the senior year $(60.53 \%)\left(\chi^{2}=172.49 ; p<0.001\right)$, the first semester (61.58\%) $\left(\chi^{2}=20.38 ; \mathrm{p}<0.001\right)$. and the first trimester (37.11\%) $\left(\chi^{2}=34.61 ; \mathrm{p}<0.001\right)$.

Table 3 presents the distribution of the players by birth year, semester, and trimester, and the team's final clas- 
sification. There was an association between birth year and the team's final classification $\left(\chi^{2}=13703, p=0.045\right)$, with the percentage of players born in the senior year being higher among the teams classified in the 1st to 4th and 9th to 16th place. There was no association between the birth semester or trimester and the team's final classification. Neither were there any associations between the birth year, semester, or trimester and the player's position $\left(5552<\chi^{2}<14227 ; 0.076<\mathrm{p}<0.564\right)$, goals scored $\left(1496<\chi^{2}<8229 ; 0.222<\mathrm{p}<0.956\right)$, or shooting effectiveness $\left(1280<\chi^{2}<5208 ; 0.648<\mathrm{p}<0.816\right)$.

TABLE 2. Number and percentage distribution by birth year, semester, and trimester for the full sample

\begin{tabular}{|c|c|c|c|c|c|c|c|c|c|c|c|c|c|c|}
\hline Year & $n$ & $\%$ & $x^{2}$ & $\mathbf{p}$ & Semester & $\mathbf{n}$ & $\%$ & $x^{2}$ & $\mathbf{p}$ & Trimester & $\mathbf{n}$ & $\%$ & $x^{2}$ & $\mathbf{p}$ \\
\hline 2000 & 230 & 60.53 & & & $\begin{array}{l}\text { S1 (January- } \\
\text { June) }\end{array}$ & 234 & 61.58 & \multirow{4}{*}{20.38} & & Q1 (January-March) & 141 & 37.11 & \multirow{4}{*}{34.61} & \multirow{4}{*}{$<0.001$} \\
\hline 2001 & 129 & 33.95 & 172.49 & $<0.001$ & $\begin{array}{l}\text { S2 (July- } \\
\text { December) }\end{array}$ & 146 & 38.52 & & $<0.001$ & Q2 (April-June) & 93 & 24.47 & & \\
\hline \multirow[t]{2}{*}{2002} & 21 & 5.52 & & & & & & & & Q3 (July-September) & 83 & 21.84 & & \\
\hline & & & & & & & & & & Q4 (October-December) & 63 & 16.58 & & \\
\hline Total & 380 & 100.00 & & & & 380 & 100.00 & & & & 380 & 100.00 & & \\
\hline
\end{tabular}

Table 4 presents the mean and SD of each variable (goals and shooting effectiveness) and the results of the one-way ANOVA depending on the team's final classification. There were differences between the teams classified from 1 st to 4 th and those classified from 9 th to 24 th place in the variables total goals, total shots, 9-m shots, fast-break goals, and fast-break shots. There were no differences in any variable between the teams classified from 1 st to 4 th and 5 th to 8 th.

TABLE 3. Number, percentage distribution, and association $\left(x^{2}\right)$ between birth year, semester, and trimester and the team's final classification

\begin{tabular}{|c|c|c|c|c|c|c|c|c|c|c|}
\hline & \multicolumn{2}{|c|}{$1^{\text {st }}$ to $4^{\text {th }}$ place } & \multicolumn{2}{|c|}{$5^{\text {th }}$ to $8^{\text {th }}$ place } & \multicolumn{2}{|c|}{$9^{\text {th }}$ to $16^{\text {th }}$ place } & \multicolumn{2}{|c|}{$17^{\text {th }}$ to $24^{\text {th }}$ place } & \multirow{2}{*}{$x^{2}$} & \multirow{2}{*}{$\mathbf{p}$} \\
\hline & $\mathbf{n}$ & $\%$ & $\mathbf{n}$ & $\%$ & $\mathbf{n}$ & $\%$ & $\mathbf{n}$ & $\%$ & & \\
\hline \multicolumn{11}{|l|}{ Year } \\
\hline 2000 & 43 & 67.19 & 44 & 68.75 & 74 & 58.27 & 70 & 56.00 & \multirow{3}{*}{13.703} & \multirow{3}{*}{0.045} \\
\hline 2001 & 20 & 31.25 & 20 & 31.25 & 47 & 37.01 & 42 & 33.60 & & \\
\hline 2002 & 1 & 1.56 & & & 6 & 4.72 & 13 & 10.40 & & \\
\hline \multicolumn{11}{|l|}{ Semester } \\
\hline S1 (January-June) & 43 & 67.19 & 39 & 60.94 & 86 & 67.72 & 66 & 52.80 & \multirow{2}{*}{6.956} & \multirow{2}{*}{0.073} \\
\hline S2 (July-December) & 21 & 32.01 & 25 & 39.06 & 41 & 32.28 & 59 & 47.20 & & \\
\hline \multicolumn{11}{|l|}{ Trimester } \\
\hline Q1 (January-March) & 24 & 37.50 & 24 & 37.50 & 55 & 43.31 & 38 & 30.40 & \multirow{4}{*}{6.214} & \multirow{4}{*}{0.750} \\
\hline Q2 (April-June) & 19 & 29.69 & 15 & 23.44 & 31 & 24.41 & 28 & 22.40 & & \\
\hline Q3 (July-September) & 12 & 18.75 & 16 & 25.00 & 21 & 16.54 & 34 & 27.20 & & \\
\hline Q4 (October-December) & 9 & 14.06 & 9 & 14.06 & 20 & 15.75 & 25 & 20.00 & & \\
\hline
\end{tabular}

Table 5 presents the mean and SD of each variable (goals and shooting effectiveness) and the results of the one-way ANOVA depending on the player's position (excluding the goalkeepers). There were differences in all the variables except total goals.

\section{Discussion}

This work has analysed the relationship between the RAE (year, semester, and trimester) and the team's final classification, player's position, number of goals scored, and shooting effectiveness. There was a greater representation of players born in the senior year, the first semester, and the first trimester among the subjects in the Women's Youth World Handball Championship. However, only the birth year had any association with the best-ranked teams, with the older players having greater representation in the teams ranked from 1st to 8th place. Both the goals scored and shooting effectiveness showed differences in terms of both the team's final classification and the player's position. To the best of our knowledge, this has been the first study of international youth handball players that has analysed the RAE, the team's final classification, player's position, number of goals scored, and shooting effectiveness.

For the total sample, the RAE was found to be present whether the data were considered by year, semester, or trimester, with the players born in the senior year, in S1, and in Q1 being more frequently represented (Table 2). This finding coincides with those of studies conducted on both women (Gómez-López et al., 2017; Schorer et al., 2009) and men (Fonseca et al., 2019; Gómez-López et al., 2017; Karcher et al., 2014; Sánchez-Rodríguez et al., 2013; Schorer et al., 2009; Wrang et al., 2018) at international (Fonseca et al., 2019; Karcher et al., 2014), national (Sánchez-Rodríguez et al., 2013; Schorer et al., 2009; Wrang et al., 2018), and regional (Gómez-López et al., 2017) levels. The association between the RAE and the team's final classification was found to depend 
TABLE 4. Mean and standard deviation of each variable. A one-way analysis of variance (ANOVA) with Tukey posthoc test was used to compare means between team classifications (Eta squared is also given)

\begin{tabular}{|c|c|c|c|c|c|c|c|c|}
\hline & $\begin{array}{c}1^{\text {st }} \text { to } 4^{\text {th }} \text { place (a) } \\
M \pm S D\end{array}$ & $\begin{array}{c}5^{\text {th }} \text { to } 8^{\text {th }} \text { place } \\
\text { (b) } \\
M \pm S D\end{array}$ & $\begin{array}{c}9^{\text {th }} \text { to } 16^{\text {th }} \text { place } \\
\text { (c) } \\
M \pm S D\end{array}$ & $\begin{array}{c}17^{\text {th }} \text { to } 24^{\text {th }} \text { place } \\
\text { (d) } \\
M \pm S D\end{array}$ & $\mathbf{F}$ & $\mathbf{p}$ & $\eta^{2}$ & Differences \\
\hline Total goals (n) & $17.63 \pm 15.89$ & $14.97 \pm 13.53$ & $9.78 \pm 11.55$ & $9.78 \pm 11.55$ & 6.880 & $<0.001$ & 0.052 & $a>c, d ; b>d$ \\
\hline Total shots (\%) & $63.32 \pm 20.08$ & $56.89 \pm 16.66$ & $51.17 \pm 21.89$ & $48.12 \pm 24.64$ & 7.005 & $<0.001$ & 0.060 & $a>c, d$ \\
\hline 6-m goals $(n)$ & $2.30 \pm 3.70$ & $2.75 \pm 4.91$ & $1.65 \pm 3.30$ & $1.45 \pm 2.72$ & 2.400 & 0.068 & 0.019 & n.s. \\
\hline 6-m shots (\%) & $47.72 \pm 42.64$ & $55.34 \pm 39.79$ & $37.04 \pm 41.30$ & $32.90 \pm 40.75$ & 5.167 & 0.002 & 0.040 & $b>c, d$ \\
\hline 7-m goals (n) & $1.88 \pm 5.23$ & $1.84 \pm 4.43$ & $1.52 \pm 3.71$ & $1.26 \pm 3.11$ & 0.481 & 0.695 & 0.004 & n.s. \\
\hline 7-m shots (\%) & $19.72 \pm 34.68$ & $28.45 \pm 41.09$ & $21.52 \pm 36.87$ & $22.38 \pm 37.44$ & 0.684 & 0.562 & 0.005 & n.s. \\
\hline 9-m goals (n) & $4.91 \pm 7.28$ & $3.70 \pm 5.65$ & $3.25 \pm 5.24$ & $3.08 \pm 5.72$ & 1.540 & 0.240 & 0.012 & n.s. \\
\hline 9-m shots (\%) & $36.45 \pm 35.54$ & $29.94 \pm 31.37$ & $21.02 \pm 24.33$ & $18.62 \pm 25.84$ & 7.083 & $<0.001$ & 0.053 & $a>c, d ; b>d$ \\
\hline Wing goals (n) & $3.03 \pm 6.84$ & $2.19 \pm 4.31$ & $1.72 \pm 3.66$ & $1.54 \pm 2.85$ & 1.929 & 0.123 & 0.015 & n.s. \\
\hline Wing shots (\%) & $30.25 \pm 39.93$ & $17.17 \pm 28.67$ & $20.38 \pm 32.14$ & $19.94 \pm 30.91$ & 2.050 & 0.106 & 0.016 & n.s. \\
\hline Fast break goals (n) & $3.19 \pm 4.11$ & $2.42 \pm 2.92$ & $1.65 \pm 2.81$ & $1.15 \pm 1.94$ & 8.214 & $<0.001$ & 0.062 & $a>c, d ; b>d$ \\
\hline Fast break shots (\%) & $57.28 \pm 43.52$ & $49.38 \pm 40.24$ & $38.83 \pm 42.44$ & $36.28 \pm 42.46$ & 4.380 & 0.005 & 0.034 & $a>c, d$ \\
\hline Breakthrough goals ( $n$ ) & $2.02 \pm 3.51$ & $1.86 \pm 2.98$ & $1.33 \pm 2.58$ & $1.19 \pm 2.41$ & 1.763 & 0.154 & 0.014 & n.s. \\
\hline Breakthrough shots (\%) & $30.61 \pm 37.37$ & $30.84 \pm 39.19$ & $32.39 \pm 42.81$ & $29.63 \pm 40.47$ & 0.099 & 0.961 & 0.001 & n.s. \\
\hline
\end{tabular}

Note. n.s., not significant.

only on the year of birth, with the teams classified from 1st to 8th place having older players than the teams classified from 9th to 24th (Table 3). This seems to highlight the relevance of the players' experience for the team's final classification (González, 2004). Some studies, however, have indicated that both men and women players from Q1 (born in January-March) tend to play more games (Bjørndal et al., 2018) and more time per game (Leonardo et al., 2018) than those born in the subsequent trimesters. No relationship was found between RAE and the player's position or goals scored. This does not agree with previous studies which have found differences in men (U19) at the international level, with there being greater representation of backs and wings born in the first and second trimesters (Fonseca et al., 2019) or in the first semester (Karcher et al., 2014). Another recent study (Alsharji, 2019) suggests that this RAE is also present in goalkeepers and centre back players.

Regarding the differences in the goals scored and shooting effectiveness depending on the classification, there were no such differences between the teams classified from 1st to 4th place and those classified from 5th to

\begin{tabular}{|c|c|c|c|c|c|c|c|c|}
\hline & $\begin{array}{c}\text { Centre back } \\
\text { (c) } \\
M \pm S D\end{array}$ & $\begin{array}{c}\text { Back } \\
\text { (b) } \\
M \pm S D\end{array}$ & $\begin{array}{l}\text { Wing } \\
(w) \\
M \pm S D\end{array}$ & $\begin{array}{l}\text { Pivot } \\
\text { (p) } \\
M \pm S D\end{array}$ & $\mathbf{F}$ & $\mathbf{p}$ & $n^{2}$ & Differences \\
\hline Total goals (n) & $16.64 \pm 14.49$ & $15.59 \pm 13.60$ & $14.15 \pm 11.51$ & $10.85 \pm 10.01$ & 2.579 & 0.054 & 0.024 & n.s. \\
\hline Total shots (\%) & $50.64 \pm 17.17$ & $47.83 \pm 20.58$ & $54.44 \pm 21.30$ & $65.51 \pm 18.96$ & 11.521 & $<0.001$ & 0.099 & $c, b, w<p$ \\
\hline 6-m goals $(n)$ & $1.30 \pm 1.52$ & $1.19 \pm 1.64$ & $0.96 \pm 1.21$ & $6.90 \pm 6.29$ & 58.842 & $<0.001$ & 0.355 & $c, b, w<p$ \\
\hline 6-m shots (\%) & $50.72 \pm 41.10$ & $40.91 \pm 43.41$ & $41.73 \pm 42.71$ & $64.46 \pm 30.19$ & 25.006 & $<0.001$ & 0.189 & $b, w<p$ \\
\hline 7-m goals ( $(n)$ & $2.78 \pm 4.63$ & $2.62 \pm 5.28$ & $1.07 \pm 3.16$ & $0.50 \pm 1.99$ & 5.547 & 0.001 & 0.049 & $c, b>p ; b>w$ \\
\hline 7-m shots (\%) & $34.84 \pm 40.15$ & $34.67 \pm 41.44$ & $15.60 \pm 35.27$ & $16.98 \pm 35.24$ & 5.544 & 0.001 & 0.049 & $c, b>w, p$ \\
\hline 9-m goals $(n)$ & $6.94 \pm 7.17$ & $6.87 \pm 6.67$ & $1.19 \pm 3.62$ & $0.97 \pm 2.32$ & 30.632 & $<0.001$ & 0.223 & $c, b>w, p$ \\
\hline 9-m shots (\%) & $35.39 \pm 21.49$ & $32.64 \pm 20.95$ & $19.64 \pm 32.89$ & $27.38 \pm 38.90$ & 4.968 & 0.002 & 0.044 & $c, b>p$ \\
\hline Wing goals (n) & $0.55 \pm 1.48$ & $0.73 \pm 2.43$ & $6.52 \pm 6.19$ & $0.33 \pm 1.10$ & 60.259 & $<0.001$ & 0.360 & $c, b, p<w$ \\
\hline Wing shots (\%) & $18.02 \pm 33.65$ & $16.00 \pm 32.25$ & $48 \pm 27.33$ & $12.18 \pm 30.66$ & 5.198 & 0.002 & 0.046 & $c, p<w$ \\
\hline Fast break goals (n) & $1.42 \pm 1.83$ & $1.65 \pm 2.21$ & $3.86 \pm 4.20$ & $1.37 \pm 2.12$ & 19.819 & $<0.001$ & 0.156 & $c, b, p<w$ \\
\hline Fast break shots (\%) & $44.45 \pm 44.64$ & $49.78 \pm 42.76$ & $60.49 \pm 36.80$ & $40.62 \pm 44.00$ & 20.159 & $<0.001$ & 0.159 & $w>p$ \\
\hline Breakthrough goals (n) & $3.47 \pm 3.47$ & $2.36 \pm 3.20$ & $0.55 \pm 1.45$ & $0.65 \pm 2.33$ & 14.907 & $<0.001$ & 0.122 & $c, b>w, p$ \\
\hline Breakthrough shots (\%) & $60.11 \pm 34.74$ & $45.48 \pm 40.20$ & $21.55 \pm 39.29$ & $16.85 \pm 36.46$ & 3.364 & 0.109 & 0.030 & $c, b>w, p$ \\
\hline
\end{tabular}

Note. n.s., not significant. 
8th place. However, there were differences between the teams classified from 1 st to 4 th and those classified from 9th to 24th in total goals, total shots, 9-m shots, fast-break goals, and fast-break shots. While differences in total goals and total shots were to be expected since these variables constitute the ultimate expression of a team's performance, the other three variables reveal important information. The effectiveness from $9 \mathrm{~m}$ (9-m shot) highlighted the importance of throws from this position, especially taking into account that, for all four groups of team classification, this position was that from which most goals were scored (Table 4). The differences in fast-break goals and fast-break shots showed the importance of rapid transitions that generate situations of superiority since these facilitate the scoring of goals (Calin, 2010). For the variables goals scored and shooting effectiveness depending on the player's position (Table 5), there were differences that reflected the specialization of the different positions (Cardinale, Whiteley, Hosny, \& Popovic, 2017). Thus, the pivots had more goals and greater effectiveness from $6 \mathrm{~m}$, reflecting the specific function of their position (Santos et al., 2009). They also had the greatest total shot effectiveness, possibly because when they throw they do so after gaining an advantage over their marker, as well as usually doing so from the central area (Zapardiel Cortés, Vila, Abraldes, Manchado, \& Ferragut, 2017). The centre back and left and right backs had more goals and greater effectiveness from $9 \mathrm{~m}$ than the other positions did. It should be noted that these players are characterized by faster throwing speeds (Shalfawi, Seiler, Tønnessen, \& Haugen, 2014). Finally, the wing players scored more goals and had greater effectiveness from the wing position than the rest of the positions did, as well as more fast-break goals, which was also found in previous studies (Michalsik, Aagaard, \& Madsen, 2015). This is because wing players spend more time during the game in sprint situations (Michalsik, Madsen, \& Aagaard, 2014) which allows them to successfully finalize fast-break situations.

The present work has a series of limitations. The first is that, although the data analysed come from the 2018 World Championship, the results might be different if the study were of another world championships or a different level championship (European Championship, Spanish Championship, etc.). The second is that the individual performance criteria (number of goals and effectiveness) bias the measured relevance of the goalkeeper since this player scores very few goals, and these data were not analysed in the study. The goalkeeper position is, however, especially important in today's handball performance (Calin, 2010).

In conclusion, it was found that, in the overall sample of players participating in the Women's Youth World Handball Championship (U18), there was an over-representation (relative age effect) of the senior year, the first semester, and the first trimester. Nevertheless, we only found an association with the classification for the year of birth, with there being more players born in the senior year (2000) in the teams classified from 1 st to 8 th place than in those classified from 9 th to 24 th. The teams classified from 1st to 4 th place had more total goals, total shots, 9-m shots, and fast-break goals and shots, indicative of the relevance of these variables for performance. All the positions (centre back, backs, wings, and pivot) had a greater number of goals and effectiveness from their specific positions. Also, we found the wings to have a greater number of goals and effectiveness in fast-break situations. Coaches might consider taking these results into account when assessing the composition of their national teams, especially thinking of the evolution of the younger players.

\section{References}

Alsharji, K. (2019, July 6). The relative age effect in handball: Its existence and influence on playing position for youth and junior teams. In V. Bunc \& E. Tsolakidis (eds.). Proceedings of the $24^{\text {th }}$ Annual Congress of the European College of Sport Science (pp.596-597). Prague (Czech Republic): ECSS.

Andronikos, G., Elumaro, A.I., Westbury, T. \& Martindale, R.J. (2016). Relative age effect: implications for effective practice. Journal of Sports Sciences, 34, 1124-1131. doi: 10.1080/02640414.2015.1093647

Balyi, I. \& Way, R. (2009). The role of monitoring growth in long-term athlete development. Vancouver, Canada: Canadian Sport Institute.

Bjørndal, C.T., Luteberget, L.S., Till, K. \& Holm, S. (2018, December). The relative age effect in selection to international team matches in Norwegian handball. PLoS ONE, 13(12), e0209288. doi: 10.1371/journal. pone. 0209288

Calin, R. (2010). The analysis of the efficiency of using fastbreaks in female handball during the World Championship in China 2009. Science, Movement and Health, 2, 594-599.

Campos, F.A.D., Stanganelli, L.C.R., Rabelo, F.N., Campos, L.C.B. \& Pellegrinotti, I.L. (2016). The relative age effect in male volleyball Championships. International Journal of Sports Science, 6(3), 116-120. doi: $10.5923 /$ j.sports.20160603.08

Cardinale, M., Whiteley, R., Hosny, A.A., \& Popovic, N. (2017). Activity profiles and positional differences of handball players during the World Championships in Qatar 2015. International Journal of Sports Physiology and Performance, 12, 908-915. doi: 10.1123/ijspp.2016-0314.

Cobley, S., Abbott, S., Eisenhuth, J., Salter, J., McGregor, D. \& Romann, M. (2019). Removing relative age effects from youth swimming: The development and testing of corrective adjustment procedures. Journal of Science and Medicine in Sport, 22(6), 735-740. doi: 10.1016/j.jsams.2018.12.013

Davis, B. D., Trimble, C. S. \& Vincent, D. R. (1980). Does age of entrance affect school achievement. The Elementary School Journal, 80(3), 133-143.

Delorme, N. \& Raspaud, M. (2009). The relative age effect in young French basketball players: a study on the whole population. Scandinavian Journal of Medicine and Science in Sports, 19(2), 235-242. doi: 10.1111/j.1600-0838.2008.00781.x 
Ferrari, W. R., Sarmento, H. \& Vaz, V. (2019). Match analysis in handball: a systematic review. Montenegrin Journal of Sports Science and Medicine, 8(2), 63-76. doi: 10.26773/mjssm.190909

Fonseca, F.S., Figueiredo, L.S., Gantois, P., de Lima-Junior, D. \& Fortes, L.S. (2019, 28). Relative age effect is modulated by playing position but is not related to competitive success in elite under-19 handball athletes. Sports, 7(4), 91. doi: 10.3390/sports7040091

Gómez-López, M., Angosto, S., Granero-Gallegos, A. \& Chirosa, L.J. (2017). Relative age effect in handball players of Murcia: Influence of sex and category of game. Journal of Human Sport and Exercise, 12(3), 565-573. doi: 10.14198/jhse.2017.123.01

González, J.M. (2004). Mes de nacimiento y éxito en el fútbol. Estudio del efecto relativo de la edad en el fútbol guipuzcoano. Osasunaz, 6, 159-184.

IHF (2018, August 20). Fixtures and results of the $7^{\text {th }}$ Women's Youth World Handball. Retrieved from http:// archive.ihf.info/en-us/ihfcompetitions/worldchampionships/ womensyouthworldchampionships/2018w omensyouth(u18)worldchampionship/fixturesandresults.aspx

Karcher, C., Ahmaidi, S. \& Buchheit, M. (2014). Effect of birth date on playing time during international handball competitions with respect to playing positions. Kinesiology, 46, 23-32.

Leite, N., Santos, S., Gonçalves, B., Silva, A., Duarte, R. \& Sampaio, J. (2018). Examining the birthdates distribution of Beijing Olympic athletes. Journal of Sport Psychology, 27(1), 31-42.

Leonardo, L., Lizana, C. J. R., Krahenbuhl, T. \& Scaglia, A. J. (2018). O efeito da idade relativa influencia o tempo de participação competitiva de atletas de handebol do sexo masculino com até 13 anos de idade. Retos: nuevas tendencias en educación física, deporte y recreación, 33, 195-198.

Melekatos, P., Vagenas, G. \& Bayios, I. (2011). A multivariate assessment of offensive performance indicators in Men's Handball: Trends and differences in the World Championships. International Journal of Performance Analysis in Sport, 11, 285-295.

Michalsik, L.B., Aagaard, P., \& Madsen, K. (2015). Technical activity profile and influence of body anthropometry on playing performance in female elite team handball. Journal of Strength and Conditioning Research, 29(4), 1126-1138. doi: 10.1519/JSC.0000000000000735

Michalsik, L.B., Madsen, K., \& Aagaard P. (2014). Match performance and physiological capacity of female elite team handball players. International Journal of Sports Medicine, 35(7), 595-607. doi: 10.1055/s0033-1358713

Sánchez-Rodríguez, C., Grande, I., Sampedro, J. \& Rivilla, J. (2013). Is the date of birth an advantage/ally to excel in handball? Journal of Human Sport and Exercise, 8, S754-S760. doi: 10.4100/jhse.2013.8.Proc3.22

Santos, F.M., Fernandez, J., Oliveira, M.C., Leitão, C., Anguera, T., \& Campaniço, J. (2009). The pivot player in handball and patterns detection - Instrument. Motricidade, 5, 29-36. doi: 10.6063/motricidade.5(3).193

Schorer, J., Baker, J., Busch, D., Wilhelm, A. \& Pabst, J. (2009). Relative age, talent identification and youth skill development: Do relatively younger athletes have superior technical skills? Talent Development and Excellence, 1(1), 45-56.

Shalfawi, S.A.I., Seiler, S., Tønnessen, E. \& Haugen, T.A. (2014). Aspects of shooting velocity in Norwegian Elite team Handball. Serbian Journal of Sports Sciences, 8, 33-40.

Wagner, H., Finkenzeller, T., Wurth, S. \& von Duvillard, S.P. (2014). Individual and team performance in team-handball: A review. Journal of Sports Science and Medicine, 13, 808-816.

Weir, P.L., Smith, K.L., Paterson, C. \& Horton, S. (2010). Canadian Women's Ice Hockey - Evidence of a relative age effect. Talent Development and Excellence, 2(2), 209-217.

Wrang, C.M., Rossing, N.N., Diernæs, R.M., Hansen, C.G., Dalgaard-Hansen, C. \& Karbing, D.S. (2018). Relative age effect and the re-selection of Danish male handball players for national teams. Journal of Human Kinetics, 63, 33-41. doi: 10.2478/hukin-2018-0004

Yague, J.M., de la Rubia, A., Sánchez-Molina, J., Maroto-Izquierdo, S. \& Molinero, O. (2018). The relative age effect in the 10 best leagues of male professional football of the Union of European Football Associations (UEFA). Journal of Sports Science and Medicine, 17, 409-416.

Zapardiel Cortés, J.C., Vila, H., Abraldes, J.A., Manchado, C. \& Ferragut, C. (2017). Analysis of the throwing speed in the different positions in the field during the competition. Journal of Human Sport and Exercise, 12, S882-S891. doi: 10.14198/jhse.2017.12.Proc3.12 